\title{
Nanoparticle Conjugation Stabilizes and Multimerizes $\beta$-Hairpin Peptides to Effectively Target PD-1/PD-L1 $\beta$-Sheet-Rich Interfaces
}

Woo-jin Jeong, ${ }^{\dagger}$ Jiyoon Bu, ${ }^{\dagger}$ Yanxiao Han,${ }^{\ddagger}$ Adam J. Drelich,${ }^{\dagger}$ Ashita Nair, ${ }^{\dagger}$ Petr Král, ${ }^{\ddagger},{ }^{\S}$ and Seungpyo Hong ${ }^{\dagger}, \|$, I, $*$

†Pharmaceutical Sciences Division and "Department of Biomedical Engineering, The University of Wisconsin-Madison, 777 Highland Ave., Madison, WI 53705, USA

"Yonsei Frontier Lab and Department of Pharmacy, Yonsei University, Seoul 03722, Republic of Korea.

Departments of Chemistry, ${ }^{\perp}$ Physics, and ${ }^{\S}$ Biopharmaceutical Sciences, University of Illinois at Chicago, Chicago, Illinois 60607, USA.

KEYWORDS. Peptide-dendrimer conjugate, $\beta$-hairpin stabilization, Multivalent binding, Immune checkpoint blockade, Cancer immunotherapy

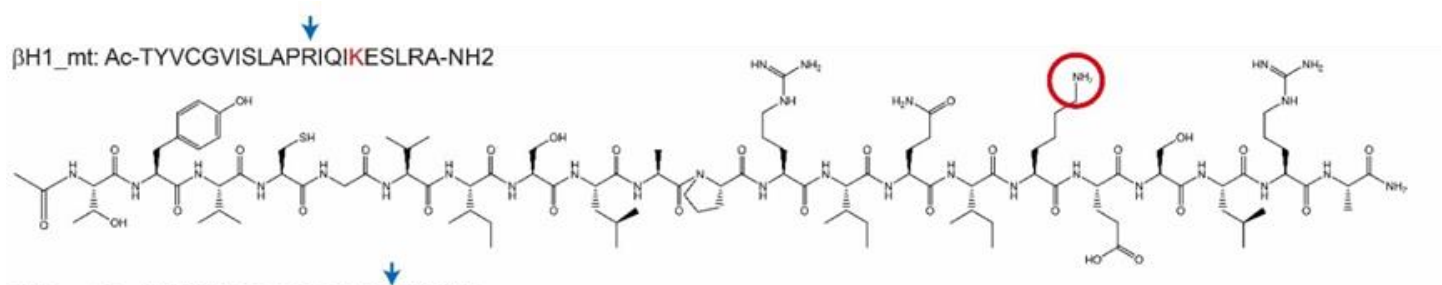

BH2_mt: Ac-HWWHRESPSGQTDTKAA-NH2

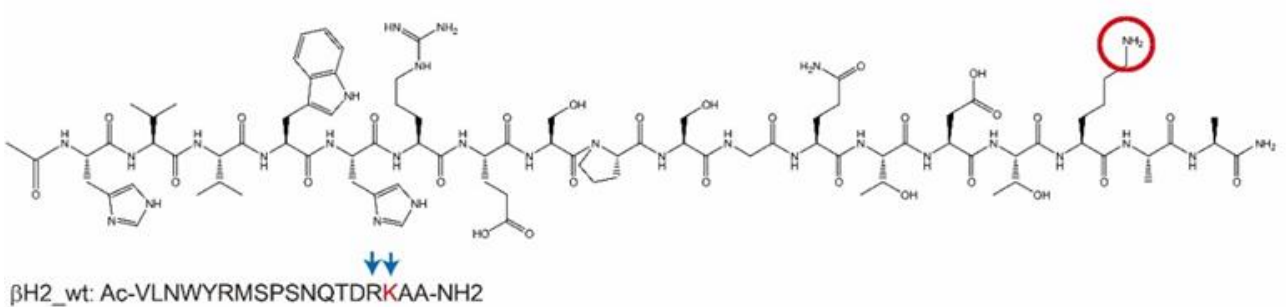

BH2 wt: Ac-VLNWYRMSPSNQTDRKAA-NH2

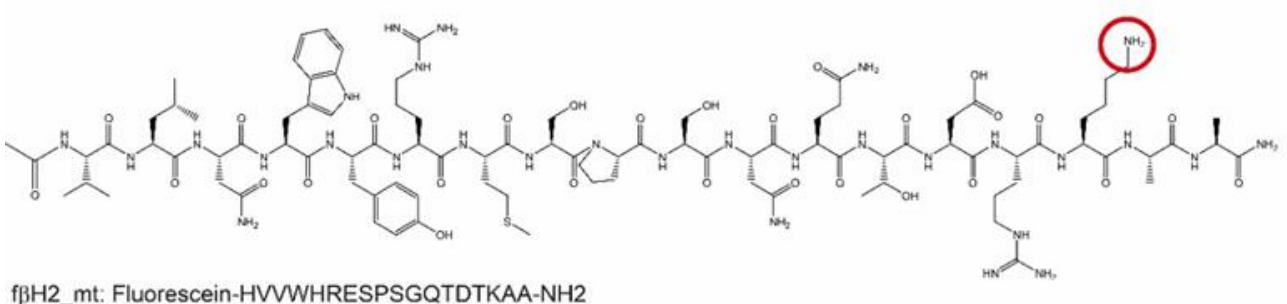

$\mathrm{fBH} 2$ _mt: Fluorescein-HWWHRESPSGQTDTKAA-NH2

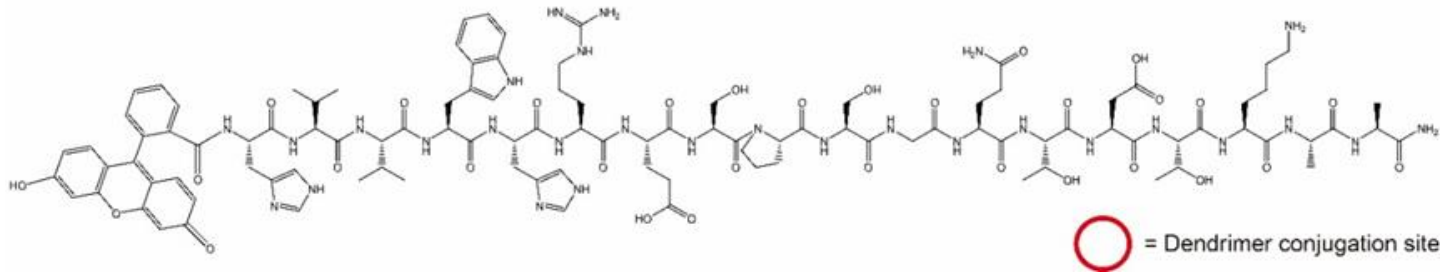

Figure S1. Chemical structures of the peptides used in this study. Blue arrows designate substituted amino acid residues for the peptide-dendrimer conjugation. The arginine residues of $\beta \mathrm{H} 1$-mt and $\beta \mathrm{H} 2$ wt were substituted for original lysine residues to prevent non-specific dendrimer conjugation, considering arginine and lysine residues possess similar physicochemical properties. 

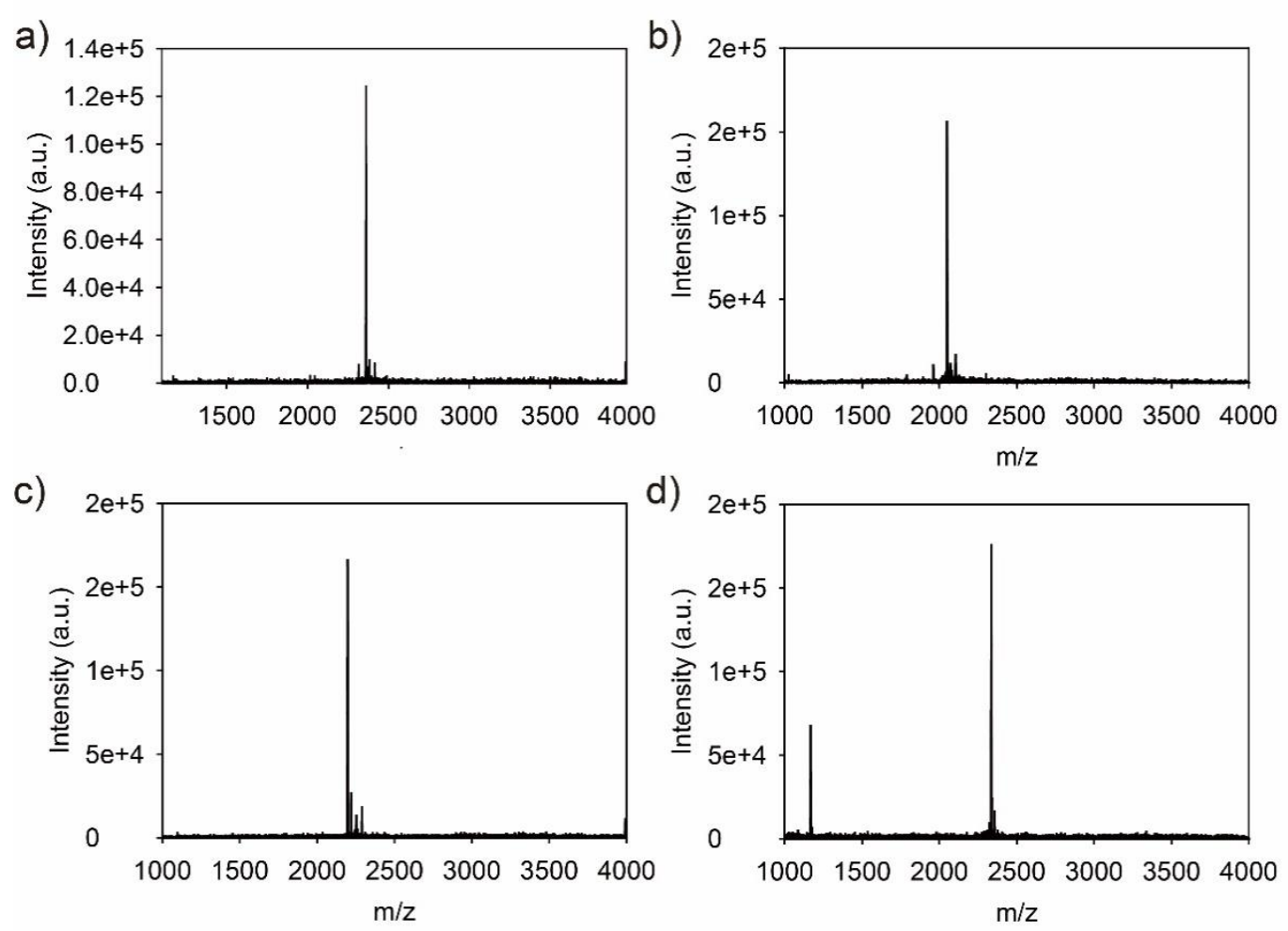

Figure S2. MALDI-TOF MS spectra of (a) $\beta \mathrm{H} 1$-mt (calculated MW: 2359.79, observed MW: 2360.30), (b) $\beta \mathrm{H} 2$-mt (calculated MW: 2048.18, observed MW: 2048.87), (c) $\beta \mathrm{H} 2$-wt (calculated MW: 2179.42, observed MW: 2179.89), and (d) fßH2-mt (calculated MW: 2364.44, observed MW: 2364.16) peptides.

a)

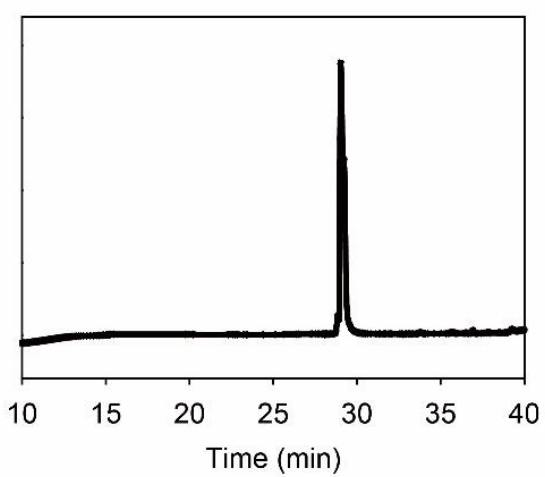

c)

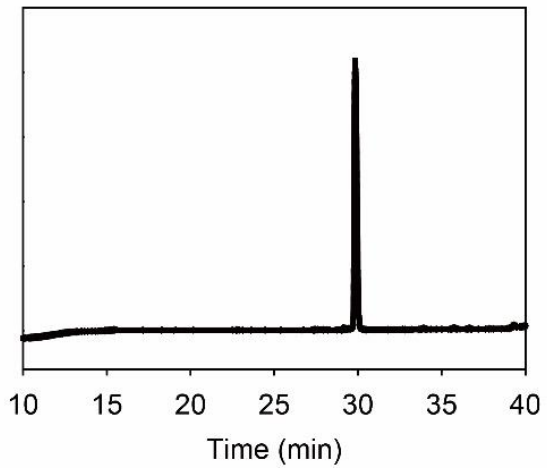

b)

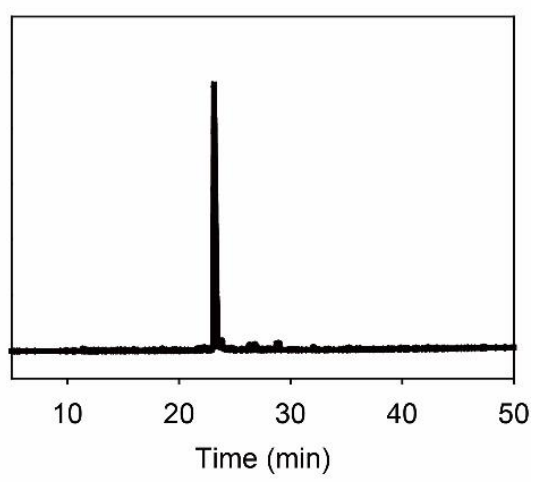

d)

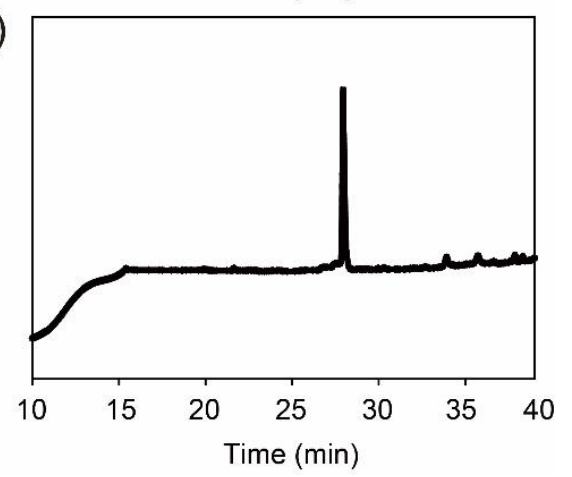

Figure S3. RP-HPLC chromatograms of the purified peptides. (a) $\beta \mathrm{H} 1-\mathrm{mt}$, (b) $\beta \mathrm{H} 2$-wt, (c) $\beta \mathrm{H} 2$-mt, and (d) $\mathrm{f} \beta \mathrm{H} 2$-mt. Condition: $\mathrm{C} 18$ column, linear gradient from $0-50 \%$ acetonitrile with $0.1 \%$ TFA, flow rate of $2 \mathrm{~mL} / \mathrm{min}$, and room temperature. 


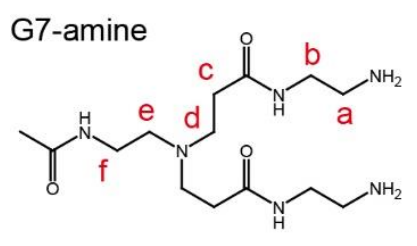

G7-acetyl-amine
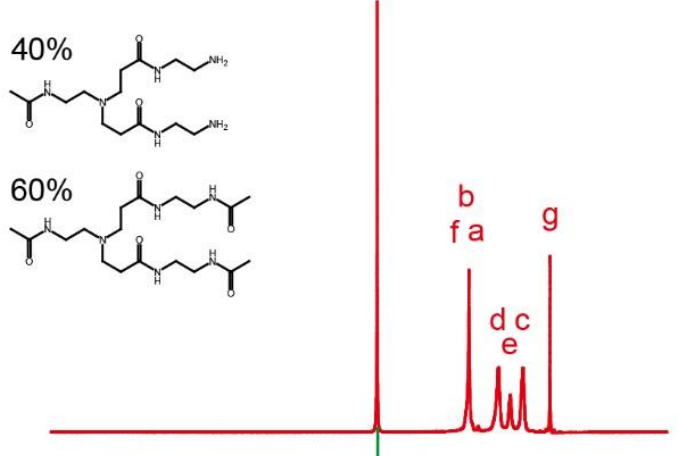

20\%

80\%
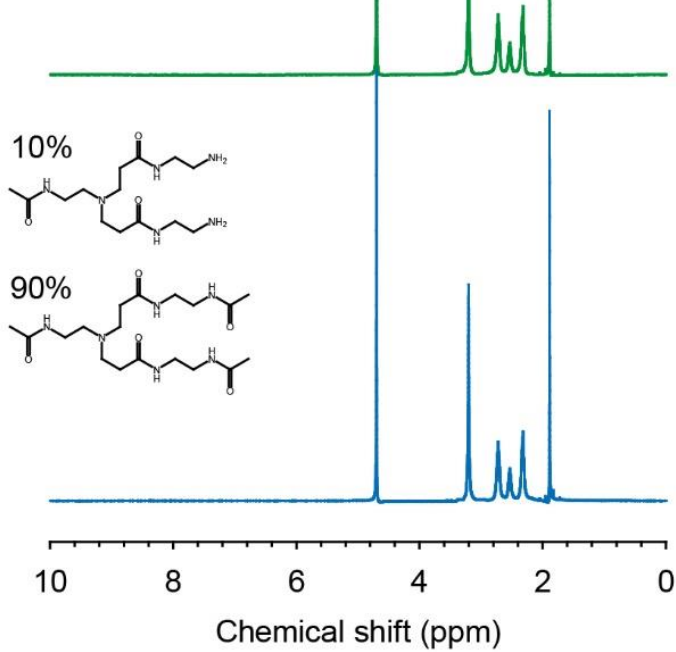<smiles>CCC(=O)NCCCN(CCC(=O)NCCNC(C)=O)CCC(=O)NCCNC(C)=O</smiles><smiles>CC(=O)NCCN(CCC(=O)NCCCNC(=O)CCC(=O)O)CCC(=O)NCCPC(=O)CCC(=O)O</smiles>

G7-acetyl-carboxyl

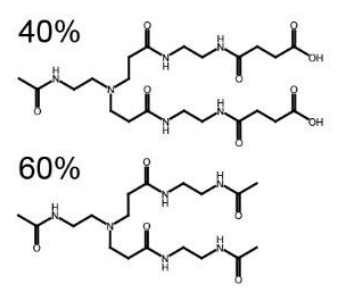

Rhodamine

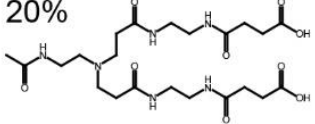

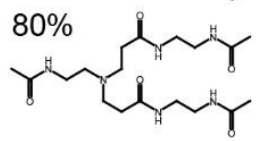

Rhodamine

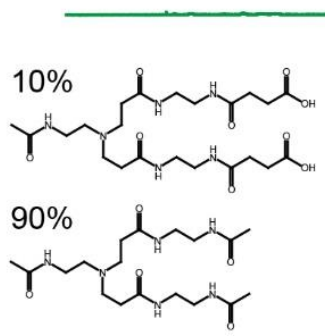

Rhodamine

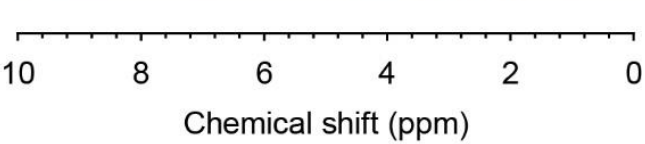

Figure S4. ${ }^{1} \mathrm{H}$ NMR spectra of surface modified G7 PAMAM dendrimers. All measurements were performed in $\mathrm{D}_{2} \mathrm{O}$ using a Bruker Advance III HD $400 \mathrm{MHz}$ NMR spectrometer. 
a)

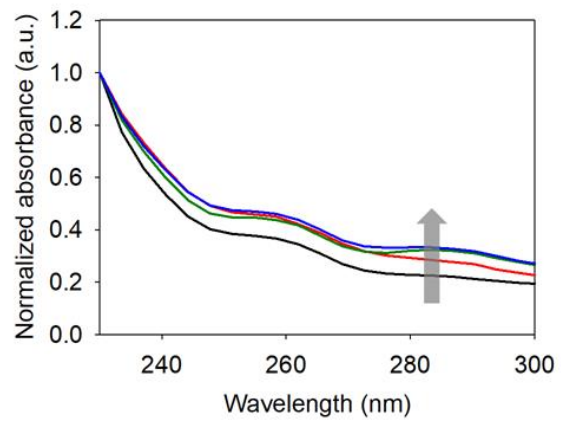

b)

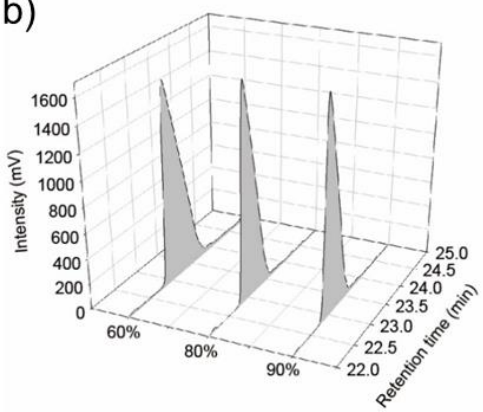

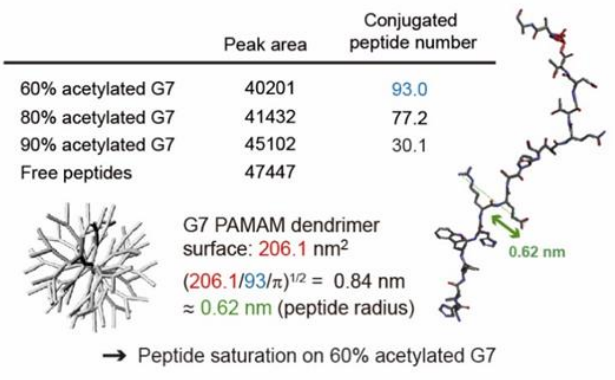

Figure S5. (a) UV absorption spectra of G7 (black, A280/A230 = 0.228), G7- $\beta \mathrm{H} 2-\mathrm{mt}$ with dendrimer acetylation degrees at $90 \%$ (red, $\mathrm{A}_{280} / \mathrm{A}_{230}=0.293$ ), $80 \%$ (green, $\mathrm{A}_{280} / \mathrm{A}_{230}=0.320$ ), and $60 \%$ (blue, $\left.\mathrm{A}_{280} / \mathrm{A}_{230}=0.333\right)$. All the materials were dissolved in PBS ( $\left.\mathrm{pH} 7.4\right)$. The increased absorbance at around $280 \mathrm{~nm}$ shows the conjugation of $\beta \mathrm{H} 2-\mathrm{mt}$ peptides including a Trp residue. (b) High performance liquid chromatography (HPLC) spectra for excess peptides following conjugation with G7 PAMAM dendrimers with various acetylation degrees at 60, 80, and 90\%. Unconjugated peptides were separated from the conjugate solution through centrifugal filtration, and the eluant, containing the free peptides, was measured. The peak area was then compared with a control free peptide baseline and the difference was used to determine the numbers of conjugated peptides. Saturation was observed at $60 \%$ acetylation. Beyond this, steric hindrance is presumed to begin, inhibiting additional peptide conjugation as the peptide radius becomes spatially similar to the space available $(0.62 \mathrm{~nm}$ compared to a max of $0.84 \mathrm{~nm}$ ).

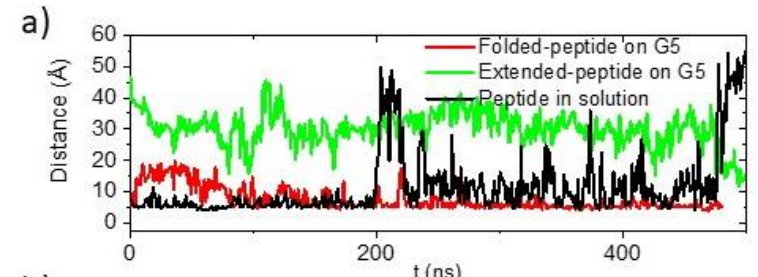

b)

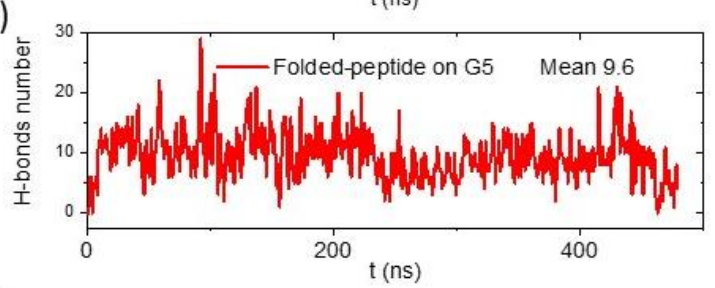

c)

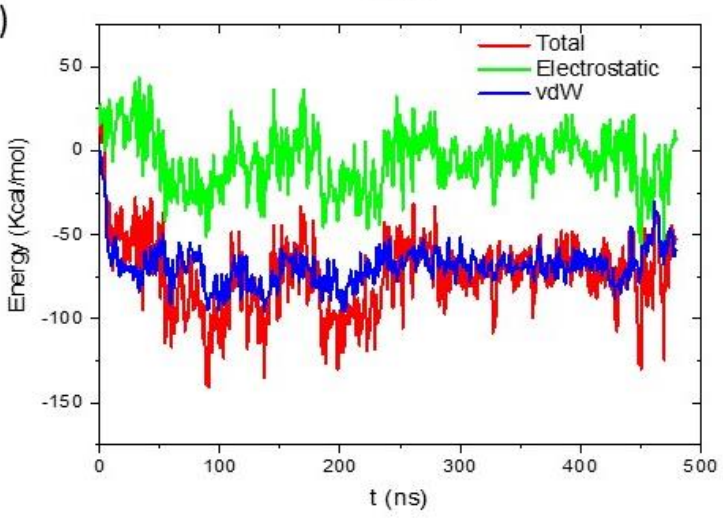

Figure S6. Molecular dynamics (MD) simulation study. (a) Distance between N- and C-termina of a $\beta \mathrm{H} 2$ mt molecule. (b) The number of hydrogen bonds (H-bonds) between a folded $\beta \mathrm{H} 2$ mt backbone and a G5 PAMAM dendrimer. (c) van der Waals and electrostatic energy between a folded $\beta \mathrm{H} 2$ mt and a G5 PAMAM dendrimer. The dielectric constant was set to one for electrostatic energy measurement to show the trend clearly. 


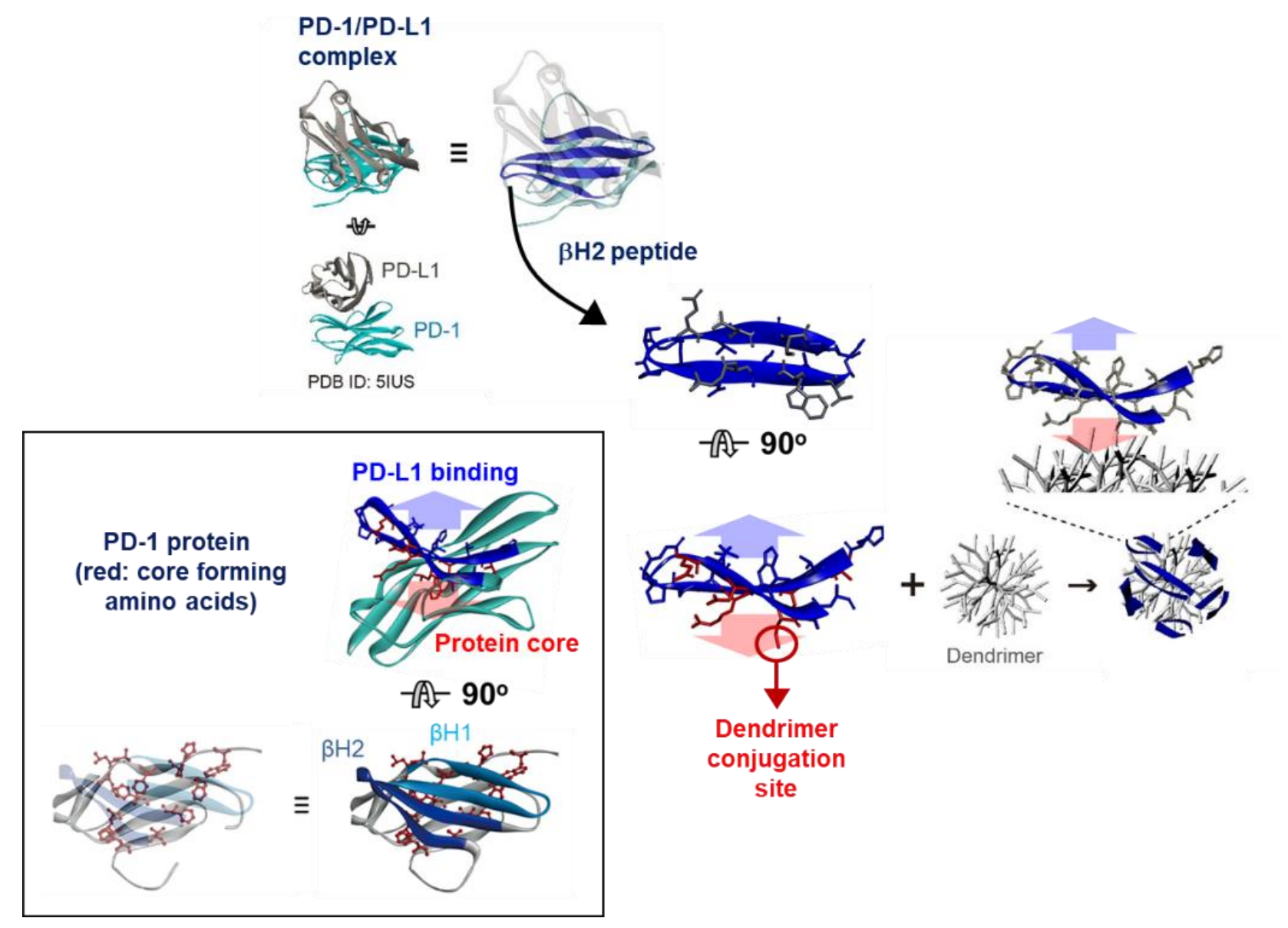

Figure S7. Comparison of molecular interactions of a $\beta \mathrm{H} 2$ peptide molecule with a PD-1 protein (in the box) and with the surface of a dendrimer molecule. As a result of the interactions, the peptide forms $\beta$ hairpin structure in the both cases.

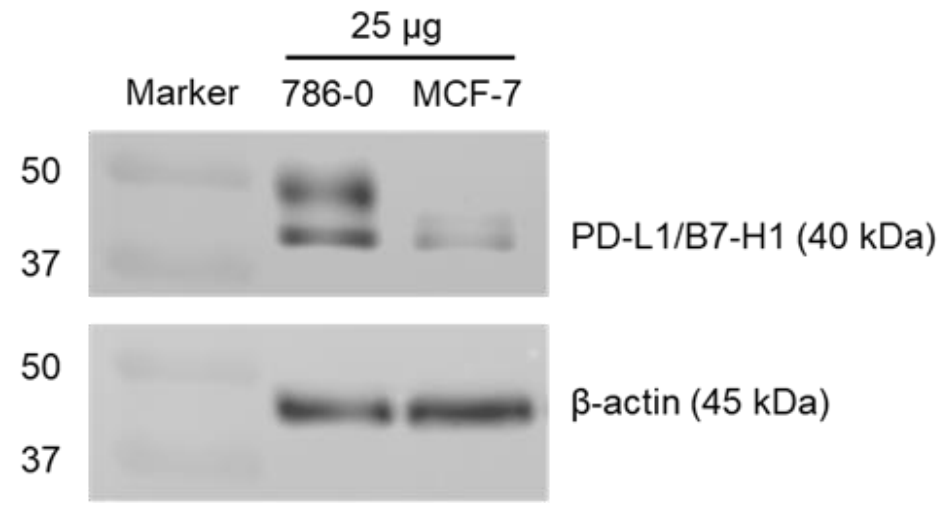

Figure S8. Western blot analysis to measure PD-L1 expression levels in 786-O and MCF-7 cells. 

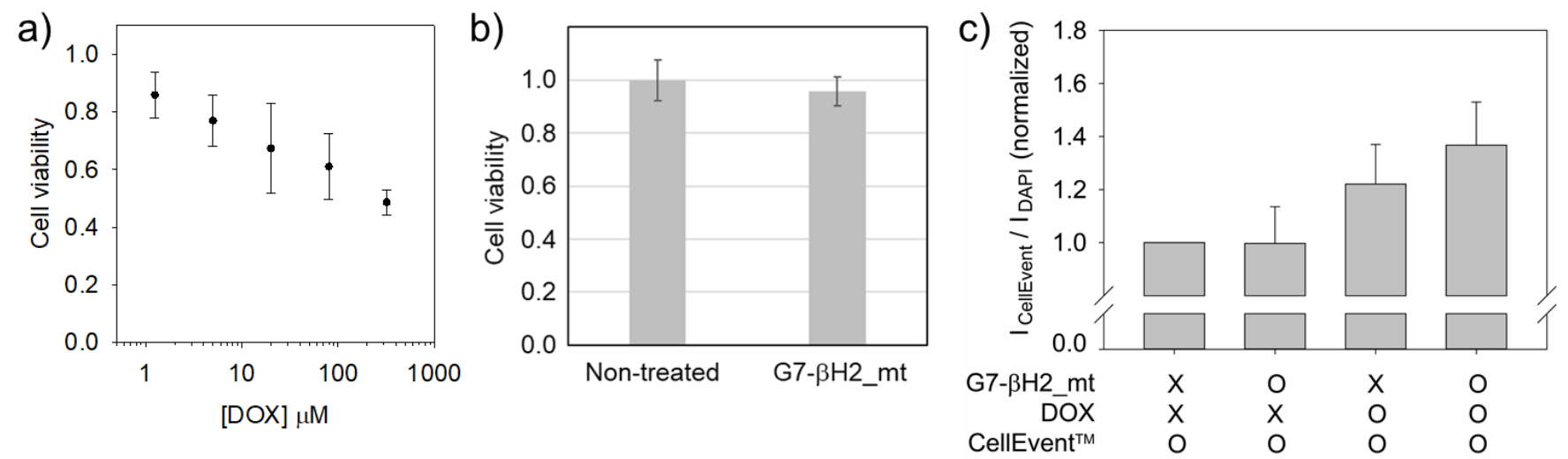

Figure S9. (a) Dose-dependent chemosensitivity of 786-O cells exposed to various concentrations of DOX $(1.25,5,20,80$, and $320 \mu \mathrm{M})$. (b) Viability of 786-O cells treated with G7- $\beta \mathrm{H} 2 \_\mathrm{mt}(33.3 \mathrm{nM})$. (c) Caspase-3/7 assay on 786-O cells co-cultured with Jurkat T cells using CellEvent ${ }^{\mathrm{TM}}$. The results indicate that the cells underwent apoptosis by the synergistic contribution of the DOX $(5 \mu \mathrm{M})$ and PDC $(33.3 \mathrm{nM})$ treatments.

\section{Experimental Section}

Peptide Synthesis. Fmoc-amino acids and coupling reagents were purchased from either Anaspec

(Fremont, CA) and Novabiochem (Germany). All other agents and general chemicals were obtained from Sigma-Aldrich (St. Louis, MO) unless noted otherwise. Rink Amide MBHA resin LL (Novabiochem, Germany) was used as scaffold for peptide synthesis. Sequences were synthesized using standard Fmoc chemistry, following previously published protocols. ${ }^{1}$ Final deprotection and cleavage of the peptide from resin involved treating the resin-bound peptide with a cleavage cocktail (trifluoroacetic acid (TFA): thioanisole: ethanedithiol (EDT) at a ratio of 95: 2.5: 2.5, $2 \mathrm{~mL}$ ) at room temperature for $2 \mathrm{~h}$ and was followed by precipitation with tert-butyl methyl ether. The resulting peptides were purified using reverse-phase HPLC at room temperature (mobile phase of water/acetonitrile with $0.1 \%$ TFA). Molecular weights of the final peptides were quantitatively measured using matrix-assisted laser desorption/ionization time-of-flight (MALDI-TOF) mass spectrometry (AXIMA, Shimadzu, Japan) with $\alpha$-Cyano-4-hydroxycinnamic acid (CHCA) as matrix. The final concentrations of all the peptide-containing solution were quantified using a ultraviolet-visible (UV-Vis) spectrophotometer in water/acetonitrile (1:1) using molar extinction coefficients for tryptophan $\left(5500 \mathrm{M}^{-1} \mathrm{~cm}^{-1}\right)$ and tyrosine $\left(1280 \mathrm{M}^{-1} \mathrm{~cm}^{-1}\right)$ at $280 \mathrm{~nm}$. 
Peptide-Dendrimer Conjugate (PDC) Preparation. G7 PAMAM dendrimers (Dendritech, Midland, MI) were purified, acetylated, and fluorescently labeled, as has been previously reported. ${ }^{2}$ Briefly, 10 mg of G7 PAMAM dendrimers dissolved in $1 \mathrm{~mL}$ methanol were acetylated by addition of acetic anhydride at 60,80 , and $90 \%$ equivalence for the number of amine groups on the dendrimer surface, along with triethylamine (TEA) at 600 molar excess of the dendrimers. The reaction was carried out under vigorous stirring at room temperature for $24 \mathrm{~h}$. Excess reagents were removed using a Vivaspin Turbo 15 (MWCO 10,000 Da, Sartorius, Germany) at 4,000 ×g for $15 \mathrm{~min}$, followed by washing with $\mathrm{ddH}_{2} \mathrm{O} 10$ times (centrifugal filtration). Acetylated dendrimers were then fluorescently labeled using Nhydroxysuccinimide rhodamine (NHS-RHO) to fluorescently quantify and visualize the nanoparticles. Dendrimers were dissolved in dimethylsulfoxide (DMSO) at a concentration of $3 \mathrm{mg} / \mathrm{mL}$, to which NHS-RHO dissolved in $100 \mu 1$ DMSO at 10-fold molar excess of the number of dendrimers was added dropwise, and then the reaction was carried out at room temperature for $24 \mathrm{~h}$. Excess reagents were removed by the centrifugal filtration (10 times). NHS-RHO labelled dendrimers were then conjugated with the peptides. Dendrimers $(1 \mathrm{mg})$ were dissolved in $1 \mathrm{~mL}$ phosphate buffered saline (PBS, $\mathrm{pH} 7.4)$, followed by addition of 1-Ethyl-3-(3-dimethylaminopropyl)-carbodiimide (EDC) and NHS (1.5-fold molar excess of dendrimer amine groups) dissolved in $100 \mu \mathrm{L}$ PBS. The solution was then vigorously stirred at room temperature for $1 \mathrm{~h}$. Finally, peptides (10-fold molar excess of dendrimer amine groups) dissolved in $1 \mathrm{~mL}$ PBS were added, and the reaction proceeded at room temperature for $24 \mathrm{~h}$. Excess peptides and reagents were removed via the centrifugal filtration using PBS 3 times.

Surface plasma resonance (SPR). SPR analysis was performed using BIAcoreX (Pharmacia Biosensor $\mathrm{AB}$, Sweden) following our previously published protocols. ${ }^{3}$ Briefly, PD-L1 proteins (R\&D systems, Minneapolis, MN) were immobilized onto the carboxylated dextran-coated gold film surface of a sensor chip (CM5 sensor chip, GE Healthcare, Chicago, IL) through the EDC/NHS chemistry. Monoclonal 
anti-PD-L1 antibodies were purchased from BioXCell (West Lebanon, NH, US). Thirty microliters (30 $\mu \mathrm{L}$ ) of sample solution was injected into the microfluidic channels at a flow of HBS-EP buffer (GE Healthcare, $20 \mu \mathrm{L} / \mathrm{min}$ ). Sample solution was allowed to flow into both channels (channel 1 for reference, channel 2 with PD-L1), and the final SPR sensorgrams were obtained by subtracting the channel 2 signal from that of channel 1. The SPR sensorgrams were fitted using the 1:1 Langmuir binding model in BIAevaluation software, as described in our previous publication. ${ }^{3}$

Peptide folding structure analysis. Circular dichroism (CD) spectra were obtained using an Aviv model 420 Circular Dichroism spectrometer (Aviv Biomedical, Lakewood, NJ). Samples (1 $\mu$ M) dissolved in $400 \mu \mathrm{M}$ PBS (pH 7.4) were analyzed from 260 to $217 \mathrm{~nm}$ using a $1 \mathrm{~mm}$ path length quartz cuvette at room temperature. Attenuated Total Reflection-Fourier Transform Infrared (ATR-FTIR) spectra (1600-1700 $\mathrm{cm}^{-1}$ ) were also collected using an Equinox 55/S FTIR spectrometer (Bruker, Billerica, MA) at room temperature.

Molecular dynamics (MD) simulation study. The systems were simulated with NAMD 4 and the CHARMM force field (CHARMM General Force Filed ${ }^{5}$ and CHARMM36 ${ }^{6}$ ) in an NPT ensemble at P = 1 bar and $\mathrm{T}=300 \mathrm{~K}$, using Langevin dynamics with a damping constant of $0.01 \mathrm{ps}-1$ and a time step of 2 fs. Long-range electrostatic interactions were calculated by the $\mathrm{PME}^{7}$ method in the presence of periodic boundary conditions. The H-bonds number was analyzed by $\mathrm{VMD}^{8}$ with a cutoff distance of $3.5 \AA$ and angle of $60^{\circ}$.

Fluorescence polarization (FP) assay. FP assay in PBS (pH 7.4) was used the PD-L1 binding and competition assays $(\lambda \mathrm{ex}=480 \mathrm{~nm} ; \lambda \mathrm{em}=535 \mathrm{~nm})$. Fluorescence anisotropy measurements were performed at room temperature, in a 384-well plate, using an Infinite M1000 Pro microplate reader 


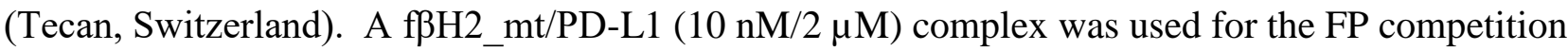
assay after $30 \mathrm{~min}$ incubation time, followed by titration with the competitors at room temperature.

Cell Culture. A human renal cell carcinoma (RCC) cell line, 786-O, and a breast cancer cell line, MCF-7, were utilized as high- and low-PD-L1 expressing cancer cell models, respectively. A human T lymphocyte cell line, Jurkat, was used in this study as a PD-1-expressing immune cell model. 786-O and Jurkat T cells were cultured in RPMI media, and MCF-7 cells were grown in DMEM media. All cell culture media were supplemented with $1 \%(\mathrm{v} / \mathrm{v})$ penicillin/streptomycin $(\mathrm{P} / \mathrm{S})$ and $10 \%(\mathrm{v} / \mathrm{v})$ fetal bovine serum (FBS). Cells were incubated under humidified atmosphere containing $5 \% \mathrm{CO}_{2}$ at $37{ }^{\circ} \mathrm{C}$.

Western Blot. The total protein lysate from 786-O and MCF-7 cells were prepared using RIPA buffer (150 mM NaCl, 1\% NP-40, 1\% sodium deoxycholate, 0.1\% SDS, 50 mM Tris-HCl, pH 7.5, 2 mM EDTA, Protease Inhibitor Cocktail II). The protein content of the lysate was quantitatively measured using BCA Assay (Pierce ${ }^{\mathrm{TM}}$ BCA Protein Assay Kit, Thermo Fisher Scientific, Waltham, MA). Twenty-five micrograms $(25 \mu \mathrm{g})$ of proteins were resolved on a 4-16\% gradient acrylamide gel and transferred onto a PVDF membrane in wet transfer conditions. The blot was probed overnight with primary antibody against PD-L1 (polyclonal anti human PD-L1, AF156, R\&D Systems) and beta-Actin (monoclonal anti-beta-Actin, MAB8929, R\&D Systems) at $4{ }^{\circ} \mathrm{C}$, followed by incubation with appropriate secondary antibodies for $1 \mathrm{~h}$ at room temperature. The proteins on the blot were detected using a chemiluminescent reagent, a Clarity Western ECL Substrate (Bio-Rad, Hercules, CA) and imaged using Syngene G:Box F3 (Syngene, Frederick, MD).

Assessment of T cell Cytokine Production. Cytokine production of Jurkat T cells was investigated in a cancer-immune cell co-culture system by assessing the amount of interleukin-2 (IL-2) secreted by T cells using a Human IL2 ELISA Kit (LifeSpan BioSiences, Seattle, WA), following the manufacturer's 
protocol. Briefly, cancer cells were incubated in 96 -well plates (5,000 cells/well) for $48 \mathrm{~h}$. Cancer cells and T cells were pre-treated with interferon- $\gamma(\mathrm{IFN} \gamma, 10 \mathrm{ng} / \mathrm{mL}$ ) and phytohaemagglutinin (PHA, 1 $\mu \mathrm{g} / \mathrm{mL}$ )/ phorbol myristate acetate (PMA, $50 \mathrm{ng} / \mathrm{mL}$ ) for $30 \mathrm{~h}$ in order to induce PD-L1 and PD-1 expressions, respectively. Cancer cells were then treated with either free peptides, free antibodies, PDCs, or other control groups ( $33.3 \mathrm{nM})$, for $6 \mathrm{~h}$, and subsequently co-cultured with Jurkat $\mathrm{T}$ cells at a 1:4 (tumor cells: Jurkat) ratio. Cell culture supernatants were collected after $48 \mathrm{~h}$ incubation and assessed for IL-2.

Chemosensitivity Assay. The chemosensitivity assay was performed by measuring the synergistic cytotoxicity effect of immune checkpoint blockade using various groups tested in this study, together with chemotherapeutic drug, doxorubicin (MedChem Express, Monmouth Junction, NJ). Cancer cells were plated in 96-well plates (5,000 cells/well) and incubated for $48 \mathrm{~h}$. Cancer cells and Jurkat T cells were pre-treated with IFN $\gamma$ and PHA/PMA as aforementioned. Cancer cells were then stained with calcein $\mathrm{AM}(1.5 \mu \mathrm{M})$, followed by $2 \mathrm{~h}$ treatment with the immune checkpoint inhibitors $(33.3 \mathrm{nM})$. The cells were co-cultured for another $24 \mathrm{~h}$ at a 1:4 ratio of tumor cells: Jurkat, prior to a doxorubicin (5 $\mu \mathrm{M})$ treatment. The effect of each group on cancer cell survival following doxorubicin treatment $(2 \mathrm{~h})$ was analyzed based on changes in fluorescent intensity using a Hitachi F-3010 Fluorescence Spectrophotometer (Japan).

Chemosensitivity depending on DOX concentration. Cell counting kit-8 (CCK-8, Abcam, Cambridge, MA) viability assay was utilized to quantitatively examine the chemosensitivity of 786-O cells to DOX. Briefly, cells were seeded in 96-well plate at $\sim 5,000$ cells/well, incubated $36 \mathrm{~h}$, and treated with IFN- $\gamma(10 \mathrm{ng} / \mathrm{mL})$ for another $24 \mathrm{~h}$. The cells were then treated with different concentration of DOX $(0-320 \mu \mathrm{M})$ for $2 \mathrm{~h}$, followed by PBS washing. Cells were incubated with $100 \mu \mathrm{L}$ of CCK-8 solution (1:10 in complete RPMI 1640 media) was added to each well and the cells were incubated 
under humidified conditions with $5 \% \mathrm{CO}_{2}$ levels at $37^{\circ} \mathrm{C}$ for $1 \mathrm{~h}$. The cell viability in each well was assessed using a Synergy HT microplate Reader (BioTek instruments, Inc., Winooski, VT), by measuring the absorbance level of each well at a detection wavelength of $450 \mathrm{~nm}$.

Caspase-3/7 Activity Assay. Following the co-culture of PHA/PMA-treated Jurkat T cells and IFN- $\gamma$ treated 786-O cells and DOX treatment, cells were labeled with $6 \mu \mathrm{M}$ caspase-3/7 green detection reagent (CellEvent ${ }^{\mathrm{TM}}$, Thermo Fisher Scientific, Waltham, MA) in complete RPMI 1640 media for $1 \mathrm{~h}$. Cells were maintained under humidified condition with $5 \% \mathrm{CO} 2$ levels at $37{ }^{\circ} \mathrm{C}$, followed by PBS washing. The fluorescent intensity in each well was assessed using a Synergy HT microplate Reader (excitation/emission wavelengths for DAPI: 358/461 nm, excitation/emission wavelengths for CellEvent: 503/530 nm).

\section{References}

[1] W. J. Jeong, S. H. Kwon, Y. B. Lim, Modular Self-Assembling Peptide Platform with a Tunable Thermoresponsiveness via a Single Amino Acid Substitution. Adv. Funct. Mater. 2018, 28. 1803114.

[2] J. Bugno, H. J. Hsu, R. M. Pearson, H. Noh, S. Hong, Size and Surface Charge of Engineered Poly(amidoamine) Dendrimers Modulate Tumor Accumulation and Penetration: A Model Study Using Multicellular Tumor Spheroids. Mol. Pharmaceut. 2016, 13, 2155.

[3] S. Hong, P.R. Leroueil, I.J. Majoros, B.G. Orr, J.R. Baker, M.M. Banazak Holl, The binding avidity of a nanoparticle-based multivalent targeted drug delivery platform. Chem. Biol. 2007, 14, 107.

[4] J. C. Phillips, R. Braun, W. Wang, J. Gumbart, E. Tajkhorshid, E. Villa, C. Chipot, R. D. Skell, L. Kale, K. Schulten, Scalable molecular dynamics with NAMD. J. Comput. Chem. 2005, 26, 1781.

[5] a) K. Vanommeslaeghe, E. Hatcher, C. Acharya, S. Kundu, S. Zhong, J. Shim, E. Darian, O. Guvench, P. Lopes, I. Vorobyov, A. D. Mackerell Jr, CHARMM General Force Field: A Force field for Drug-Like Molecules Compatible with the CHARMM All-Atom Additive Biological Force Field. Comput. Chem. 2010, 31, 671.; b) K. Vanommeslaeghe, A. D. MacKerell Jr, Automation of the CHARMM General Force Field (CGenFF) I: bond perception and atom typing. J. Chem. Inf. Model. 2012, 52, 3144 .

[6] a) A. D. MacKerell Jr, D. Bashford, M. Bellott, R. L. Dunbrack Jr., J. D. Evanseck, M. J. Field, S. Fischer, J. Gao, H. Guo, S. Ha, D. Joseoh-McCarthy, L. Kuchnir, K. Kuczera, F. T. K. Lau, C. Mattos, S. Michnick, T. Ngo, D. T. Nguyen, B. Prodhom, I. Reiher, All-atom empirical potential for molecular modeling and dynamcis Studies of proteins. J. Phys. Chem. B 1998, 102, 3586; b) A. D. MacKerell Jr, 
M. Feig, C. L. Brooks, Extending the treatment of backbone energetics in protein force fields: limitations of gas-phase quantum mechanics in reproducing protein conformational distributions in molecular dynamics simulations. J. Comput. Chem. 2004, 25, 1400.

[7] T. Darden, D. York, L. Pedersen, Particle mesh Ewald: An N $\cdot \log (\mathrm{N})$ method for Ewald sums in large systems. J. Chem. Phys. 1993, 98, 10089.

[8] W. Humphrey, A. Dalke, K. Schulten, VMD: visual molecular dynamics. J. Molec. Graphics 1996, 14,33 . 